\title{
MENINGKATKAN HASIL BELAJAR MATEMATIKA SISWA MELALUI PEMBELAJARAN MULTIMEDIA INTERAKTIF DENGAN MODEL DISCOVERY LEARNING
}

\author{
Dian Puspita Aprilia Laknasa ${ }^{1}$, Abdul Wahab Abdullah ${ }^{2}$, Khardiyawan A. Y. Pauweni $^{3}$, \\ Kartin Usman ${ }^{4}$, Abas Kaluku ${ }^{5}$ \\ 1,2,3,4,5 Jurusan Matematika, Universitas Negeri Gorontalo, Bone Bolango 96119, Indonesia \\ *Penulis Korespondensi. Email: dianlaknasa@gmail.com
}

\begin{abstract}
Abstrak
Penelitian ini bertujuan untuk meningkatkan hasil belajar matematika siswa pada materi bangun ruang bola melalui pembelajaran multimedia interaktif dengan model discovery learning. Penelitian ini adalah jenis penelitian tindakan kelas yang dilaksanakan di MTs Negeri 2 Boalemo pada tahun ajaran 2019-2020. Penelitian dilaksanakan dengan melibatkan 21 siswa sebagai subjek penelitian. Istrumen yang digunakan berupa lembar pengamatan kegiatan guru, lembar pengamatan kegiatan siswa, dan tes hasil belajar. Hasil pengamatan kegiatan guru menunjukkan kategori minimal baik atau sangat baik dengan presentase $87,50 \%$ sedangkan hasil pengamatan kegiatan siswa menunjukkan kategori minimal baik atau sangat baik dengan presentase $91,00 \%$. Adapun tes hasil belajar menunjukkan bahwa banyaknya siswa yang mencapai nilai Kriteria Ketuntasan Minimal adalah 19 siswa $(90,50 \%)$ dan tidak tuntas sebanyak 2 orang siswa $(9,50) \%$. Selanjutnya, rata-rata hasil belajar matematika siswa pada materi bangun ruang bola sebesar $89,00 \%$ dan telah memenuhi indikator keberhasilan belajar.
\end{abstract}

Kata Kunci: Multimedia Interaktif; Hasil Belajar Matematika; Bola; Discovery Learning

\begin{abstract}
This study aims to improve students' mathematics learning outcomes in sphere materials through interactive multimedia learning with discovery learning models. This research is a type of classroom action research conducted at MTs Negeri 2 Boalemo in the 2019-2020 school year. The study was carried out by involving 21 students as research subjects. The instruments used were in the form of teacher activity observation sheets, student activity observation sheets, and learning outcomes tests. The results of observations of teacher activities show a minimum category of good or very good with a percentage of $87.50 \%$. In comparison, the results of observations of student activities show a minimum classification of good or very good with a percentage of $91.00 \%$. The learning outcomes test showed that the number of students who achieved the Minimum Completeness Criteria was 19 students (90.50\%), and 2 students did not complete (9.50\%). Furthermore, the average mathematics learning outcomes of students on the sphere material are $89.00 \%$ and have met the indicators of learning success.
\end{abstract}

Keywords: Interactive Multimedia; Mathematics Learning Outcomes; Sphere; Discovery Learning

\section{Pendahuluan}

Perkembangan teknologi serta aplikasi disegala bidang menuntut kita menguasai teknologi informasi dan pengetahuan. Perkembangan teknologi informasi dan pengetahuan dapat dimanfaatkan dalam pengembangan pembelajaran untuk menunjang kemajuan dalam dunia pendidikan khususnya dalam pembelajaran matematika agar lebih efektif dan efisien. Matematika memiliki peranan sebagai ilmu dasar dalam aspek teori maupun aspek terapan dalam peningkatan penguasaan sains dan 
teknologi, serta menjadi bagian dari tolak ukur kemajuan ilmu pengetahuan [1]. Matematika sebagai bagian dari science merupakan sebuah ilmu pengetahuan yang diperoleh dari proses belajar. Karakteristik matematika yang abstrak membuat pelajaran ini tidak mudah dipahami. Belajar matematika tidak cukup mengenal konsep namun dapat menggunakan konsep tersebut untuk menyelesaikan masalah baik masalah yang berhubungan dengan matematika maupun masalah dalam kehidupan sehari-hari. Hal ini direfleksikan melalui pemisalan dimana siswa mampu mendefinisikan kembali bahan pembelajaran matematika dengan bahasa mereka sendiri, mampu mengklasifikasikan contoh serta bukan contoh [2].

Proses pembelajaran harus didukung oleh peristiwa-peristiwa baik yang terjadi di dalam maupun luar diri siswa. Pengaruh proses pembelajaran yang baik dapat memberikan motivasi, mengarahkan perhatian, memberi umpan balik untuk menyempurnakan kegiatan belajar sehingga mempengaruhi hasil belajar siswa. Dalam proses pembelajaran, hasil belajar dipengaruhi oleh kualitas pengajaran. Guru memiliki peran dan tanggung jawab untuk menguasai ilmu yang diajarkan. Guru sebagai pengelola pembelajaran harus mengatur kondisi belajar sedemikian rupa sehingga menghasilkan proses belajar yang efektif dan siswa dapat belajar sesuai dengan tujuan yang akan dicapai [3]. Dengan demikian seorang guru tidak hanya dituntut pandai atau menguasai suatu ilmu, akan tetapi harus dapat merancang pembelajaran, mengembangkan bahan ajar, serta dapat melaksanakan proses pembelajaran dengan baik [4].

Hasil belajar mempunyai peranan penting dimana hasil belajar merupakan gambaran keberhasilan siswa dalam belajar. Hasil belajar siswa pada hakikatnya adalah perubahan tingkah laku. Tingkah laku sebagai hasil belajar dalam pengertian yang luas, mencakup bidang kognitif, efektif, dan psikomotorik [5]. Hasil belajar matematika siswa bukan sesuatu yang sepenuhnya tergantung pada guru melainkan harus keluar dari diri siswa itu sendiri. [6]. Dalam proses pembelajaran untuk mengetahui tingkat keberhasilan belajar siswa biasanya dilakukan tes untuk menilai hasil belajar yang dicapai siswa dalam mata pelajaran yang diberikan [7]. Proses penilaian terhadap hasil belajar siswa dapat memberikan informasi kepada guru tentang kemajuan siswa dalam upaya mencapai tujuantujuan belajarnya melalui kegiatan belajar. Pada dasarnya, pembelajaran matematika akan berhasil apabila guru mengetahui karakteristik dari matematika itu sendiri. Melalui pembelajaran matematika, siswa seharusnya disiapkan agar memiliki kemampuan berpikir logis, kritis, analitik, serta sistematis. Salah cara untuk membentuk siswa memiliki kemampuan-kemampuan matematika yang menekankan pada aspek tersebut adalah menciptakan suatu proses pembelajaran yang efektif sehingga hasil belajar siswa dapat ditingkatkan [8].

Dalam pelaksanaan pembelajaran, usaha untuk meningkatkan hasil belajar siswa mengalami kendala dalam pembelajaran matematika yang menuntut siswa memahami materi dan juga dapat menerapkannya. Dalam pembelajaran matematika proses eksternal dilalui melalui interaksi antar siswa, perangkat pembelajaran, dan guru. Namun kenyataan di sekolah-sekolah, kemampuan guru menggunakan metode pembelajaran yang bervariasi masih rendah, guru lebih banyak mengajar sebatas menjawab soal-soal, guru memiliki kecenderuangan menggunakan metode mengajar yang tidak efektif, dan guru lebih banyak menggunakan metode pembelajaran langsung tanpa memperhatikan aspek efektif, kognitif dan psikomotorik siswa secara komprehensif [9]. Kondisi ini juga yang terjadi pada siswa kelas IX-4 MTs Negeri 2 Boalemo yang ditunjukkan dengan presentase hasil belajar matematika siswa pada materi bola yang masih dibawah Kriteria Ketuntasan Minimal (KKM). Hal ini disebabkan oleh penggunaan model pembelajaran yang masih didominasi oleh guru sehingga siswa masih kurang aktif serta penggunaan media pembelajaran yang masih jarang dilakukan sehingga menyebabkan siswa masih sulit memahami materi yang diajarkan dan kurang menarik minat siswa dalam belajar dan menyebabkan rendahnya hasil belajar matematika siswa.

Pemanfaatan teknologi yang ada berupa media pembelajaran berbasis multimedia pembelajaran interaktif menjadi salah satu inovasi yang dapat dilakukan, sehingga dapat membantu guru mengajar dan menyampaikan materi. Penggunaan multimedia dalam proses pembelajaran dapat membantu guru dalam menyampaikan materi yang diajarkan dan membuat variasi dalam mengajar agar tercipta suasana pembelajaran yang menyenangkan serta waktu yang digunakan lebih efisien [10]. 
Penggunaan multimedia pembelajaran interaktif dapat menambah motivasi siswa dalam belajar sehingga berpengaruh terhadapa hasil belajar matematika itu sendiri, seperti yang terdapat pada [11][12]. Demikian halnya penggunaan multimedia interaktif juga telah banyak digunakan dalam pembelajaran, seperti yang terdapat pada [13]-[15]. Serta penggunaan model pembelajaran discovery learning yang menunjang multimedia pembelajaran itu sendiri untuk membangun pengetahuan siswa. Dalam pembelajaran matematika dengan menggunakan model pembelajaran discovery, diharapkan siswa dapat menemukan konsep-konsep dan prinsip-prinsip melalui proses mentalnya sendiri [16].

Banyaknya penelitian terkait multimedia pembelajaran interaktif dalam pembelajaran menunjukan bahwa multimedia pembelajaran interaktif dapat menjadi solusi dalam meningkatkan hasil belajar matematika. Namun dalam beberapa penelitian yang disebutkan sebelumnya belum ada yang mengaitkan multimedia pembelajaran interaktif dengan model discovery learning khususnya membahas topik materi bola. Oleh karena itu pada makalah ini dilakukan upaya meningkatkan hasil belajar matematika siswa melalui pembelajaran multimedia interaktif dengan model discovey learning pada materi bola.

\section{Metode Penelitian}

Metode yang digunakan dalam penelitian ini adalah penelitian tindakan kelas. Data yang dikumpulkan berupa observasi kegiatan guru, observasi kegiatan siswa, dan tes hasil belajar. Sebelum disebarkan, beberapa instrumen tersebut di uji validitas dan reliabilitasnya. Data hassil belajar didapat melalui multimedia pembelajaran interaktif yang dilihat dari aktivitas guru dan aktivitas siswa, sedangkan tes hasil belajar diperoleh dengan mengukur presentase dengan menggunakan rumus presentase rata-rata

$$
\bar{x}=\frac{\sum_{i=1}^{a} X i}{n}
$$

Nilai yang diperoleh peserta didik dianalisis dan diolah dengan cara menghitung jumlah siswa yang mencapai Kriteria Ketuntasan Minimal (KKM) secara individu maupun klasikal kemudian dihitung presentase ketuntasan. Kriteria ketuntasan hasil belajar siswa diberikan pada Tabel 1.

Tabel 1. Kriteria Ketuntasan Siswa

\begin{tabular}{cc}
\hline Skor $(\bar{x})$ & Kriteria \\
\hline $\bar{x}<75$ & Tidak Tuntas \\
$\bar{x} \geq 75$ & Tuntas \\
\hline
\end{tabular}

\section{Hasil dan Pembahasan}

\subsection{Hasil}

Hasil penelitian yang ditunjukan melalui instrumen lembar pengamatan kegiatan guru, lembar pengamatan kegiatan siswa, dan tes hasil belajar ditunjukan pada Tabel 2 .

Tabel 2. Presentase Hasil Pengamatan Kegiatan Guru

\begin{tabular}{|c|c|c|c|c|c|}
\hline \multirow{3}{*}{$\begin{array}{l}\text { Kriteria } \\
\text { Penilaian }\end{array}$} & \multicolumn{4}{|c|}{ Presentase Jumlah Aspek } & \multirow{3}{*}{$\begin{array}{c}\text { Presentase } \\
\text { Rata-rata }\end{array}$} \\
\hline & \multicolumn{2}{|c|}{ Pertemuan 1} & \multicolumn{2}{|c|}{ Pertemuan 2} & \\
\hline & Jumlah Item & Presentase & Jumlah Item & Presentase & \\
\hline Sangat Baik & 1 & $10 \%$ & 5 & $50 \%$ & $30 \%$ \\
\hline Baik & 5 & $50 \%$ & 5 & $50 \%$ & $50 \%$ \\
\hline Cukup & 4 & $40 \%$ & - & - & $20 \%$ \\
\hline Kurang & - & - & - & - & - \\
\hline Jumlah & 10 & $100 \%$ & 10 & $100 \%$ & $100 \%$ \\
\hline
\end{tabular}


Dari Tabel 2 dapat diketahui bahwa kemampuan guru dalam mengelola pembelajaran menggunakan multimedia pembelajaran interaktif dengan total capaian asspek keseluruhan mencapai indikator baik atau sangatt baik yakni $80 \%$.

Tabel 3. Presentase Hasil Pengamatan Kegiatan Siswa

\begin{tabular}{|c|c|c|c|c|c|}
\hline \multirow{3}{*}{$\begin{array}{l}\text { Kriteria } \\
\text { Penilaian }\end{array}$} & \multicolumn{4}{|c|}{ Presentase Jumlah Aspek } & \multirow{3}{*}{$\begin{array}{c}\text { Presentase } \\
\text { Rata-rata }\end{array}$} \\
\hline & \multicolumn{2}{|c|}{ Pertemuan 1} & \multicolumn{2}{|c|}{ Pertemuan 2} & \\
\hline & Jumlah Item & Presentase & Jumlah Item & Presentase & \\
\hline Sangat Baik & - & - & 4 & $67 \%$ & $33,33 \%$ \\
\hline Baik & 4 & $67 \%$ & 2 & $33 \%$ & $50 \%$ \\
\hline Cukup & 2 & $33 \%$ & - & - & $16,67 \%$ \\
\hline Kurang & - & - & - & - & - \\
\hline Jumlah & 6 & $100 \%$ & 6 & $100 \%$ & $100 \%$ \\
\hline
\end{tabular}

Pada Tabel 3 dapat dilihat bahwa rata-rata kegiatan siswa selama proses pembelajaran berlangsung dengan menggunakan multimedia pembelajan interaktif, secara keseluruhan mencapai indikator capaian baik atau sangat baik yakni $83,33 \%$.

Tabel 4. Tes Hasil Belajar Siswa

\begin{tabular}{cccc}
\hline Jumlah Siswa & Tuntas & Tidak Tuntas & Rata-rata \\
\hline 21 & 19 & 2 & $89 \%$ \\
\hline
\end{tabular}

Berdasarkan Tabel 4 tes hasil belajar siswa setelah diterapkan pembelajaran dengan menggunakan multimedia pembelajaran interaktif menunjukkan bahwa dari 21 siswa diperoleh 19 siswa yang mencapai ketuntasan dan 2 siswa tidak tuntas dengan perolehan rata-rata 89\%, sehingga sudah memenuhi kriteria penilaian hasil belajar.

Tabel 5. Hasil Pelaksanaan Tindakan

\begin{tabular}{clc}
\hline No & \multicolumn{1}{c}{ Sumber } & Hasil Capaian \\
\hline 1 & Lembar Pengamatan Kegitan Guru & $87,5 \%$ \\
2 & Lembar Pengamatan Kegiatan Siswa & $91 \%$ \\
3 & Tes Hasil Belajar & $90 \%$ \\
\hline
\end{tabular}

Berdasarkan Tabel 5 hasil pelaksanaan tindakan setelah diterapkan pembelajaran dengan menggunakan multimedia pembelajaran interaktif menunjukan bahwa hasil capaian pengamatan kegiatan guru $87,5 \%$, pengamatan kegiatan siswa 91\%, dan tes hasil belajar 90\%, sehingga sudah memenuhi indikator keberhasilan baik atau sangat baik.

\subsection{Pembahasan}

Penelitian Tindakan Kelas (PTK) pada siswa kelas IX-4 MTs Negeri 2 Boalemo dengan tujuan meningkatkan hasil belajar matematika siswa pada materi bola yaitu dapat ditingkatkan dengan Multimedia Pembalajaran Interaktif dengan model discovery learning. Pada pertemuan pertama pengamatan kegiatan guru didapatkan 4 aspek dengan kategori cukup (C) yaitu guru cukup baik dalam memotivasi siswa melalui multimedia pembelajaran interaktif, guru cukup baik dalam mendorong siswa menyimak dengan seksama pelajaran yang disajikan, guru cukup baik dalam menumbuhkan keceriaan dan antusiasme siswa dalam penggunaan multimedia dan guru cukup baik dalam melakukan refleksi pelajaran dengan melibatkan siswa.

Kemudian pada pertemuan kedua, 4 aspek dengan kategori cukup (C) tersebut tersebut mulai berkurang menjadi 0 aspek. Pada pertemuan kedua ini, guru sudah mulai merefleksi diri yaitu dengan 
mengevaluasi hasil yang telah di dapatkan pada pertemuan pertama. Pendekatan guru terhadap siswa mulai meningkat. Guru lebih baik dalam memotivasi siswa dan memusatkan perhatian siswa. Guru juga lebih bisa mengarahkan siswa dalam mengoperasikan secara langsung multimedia pembelajaran sesuai dengan apa yang disampaikan guru, sehingga siswa menjadi telibat aktif dalam proses pembelajaran. Hal ini juga berpengaruh terhadap aktivitas siswa itu sendiri. Aktivitas belajar siswa dipengaruhi oleh faktor internal maupun faktor eksternal. Meningkatnya aktivitas belajar siswa diharapkan sejalan dengan meningkatnya pemahaman siswa akan suatu materi tersebut. Sehingga kegiatan mengamati, mengumpulkan informasi, dan menyelesaiakan masalah lebih mudah dilakukan siswa, serta lebih menumbuhkan keceriaan siswa dalam penggunaan multimedia pembelajaran interaktif.

Kemudian pada pertemuan pertama lembar pengamatan kegiatan guru, didapatkan 1 aspek dengan kategori sangat baik (SB) yaitu, guru sangat baik dalam menjelaskan langkah-langakah penggunaan multimedia pembelajaran interaktif. Pada pertemuan kedua aspek tersebut meningkat menjadi 5 aspek dengan kategori sangat baik (SB) yaitu, guru sangat baik dalam menjelaskan langkah-langkah penggunaan multimedia pembelajaran interaktif, guru sangat baik dalam meminta siswa mengoperasikan secara langsung multimedia pembelajaran interaktif, guru menumbuhkan partisipasi aktif siswa dalam penggunaan multimedia pembelajaran interaktif, guru sangat baik baik dalam meminta siswa menyelesaikan Lembar Kerja Peserta Didik (LKPD), guru sangat baik dalam membimbing siswa menyelesaikan Lembar Kerja Peserta Didik (LKPD). Hal ini berpengaruh terhadap aktivitas siswa itu sendiri dimana terdapat 4 aspek dengan kategori sangat baik (SB) yaitu, siswa sangat baik dalam menyelesaikan masalah terkait bola dalam Lembar Kerja Peserta Didik (LKPD), siswa sangat baik dalam mengoperasikan secara langsung multimedia pembelajaran interaktif, siswa sangat baik dalam menyelesaikan latihan pada multimedia pembelajaran interaktif, dan siswa sangat ceria dan antusias dalam proses pembelajaran dengan menggunakan multimedia pembelajaran interaktif.

Berdasarkan hasil penelitian dapat dilihat pada pelaksanaan penelitian tindakan kelas yang dilakukan dengan menggunakan Multimedia Pembelajaran Interaktif pada siklus I sudah mencapai indikator keberhasilan yang diharapkan, sehingga peneliti tidak melanjutkan pada siklus II atau selanjutnya. Sehingga dapat simpulkan dalam pembelajaran matematika materi bola jika menggunakan multimedia pembelajaran interaktif dengan model discovery learning maka hasil belajar matematika siswa dapat meningkat.

\section{Kesimpulan}

Hasil belajar matematika siswa pada materi bola dapat ditingkatkan setelah dilakukan tindakan dengan menggunakan Pembelajaran Multimedia Interaktif dengan model discovery learning. Peningkatan rata-rata hasil belajar matematika pada materi bola ditunjukkan dengan capaian hasil belajar siswa sebanyak 19 siswa atau sekitar 90,50\% yang mencapai ketuntasan belajar sementara hanya terdapat 2 siswa atau sekitar 9,50\% yang tidak tuntas. Hasil ini juga didukung dengan rata-rata hasil belajar matematika pada materi bola yang sudah memenuhi indikator keberhasilan dengan 89\% dari seluruh siswa yang mengikuti pembelajaran mencapai nilai Kriteria Ketuntasan Minimal.

\section{Referensi}

[1] A. Yahya, N. W. Bakri, "Pembelajaran Kooperatif Tipe Rotating Trio Exchange untuk Meningkatkan Aktifitas dan Hasil Belajar Matematika siswa," Jurnal Analisa., vol. 6, no. 1, 2020.

[2] S. Khadijah, S. Ismail, and R. Resmawan, "Pengembangan Bahan Ajar Berbasis Penalaran pada Materi Sudut Pusat dan Sudut Keliling Lingkaran," Al-Khwarizmi J. Pendidik. Mat. dan Ilmu Pengetah. Alam, vol. 8, no. 1, pp. 1-12, Apr. 2020, doi: 10.24256/jpmipa.v8i1.838.

[3] A. A. Jeheman, B. Gunur, and S. Jelatu, "Pengaruh Pendekatan Matematika Realistik terhadap 
Pemahaman Konsep Matematika Siswa," Mosharafa., vol. 8, no. 2, Mei 2019.

[4] C. Ainy, U. Arifah, "Meningkatkan Aktivitas dan Hasil Belajar Siswa Kelas VIII SMP Muhammadiyah 10 Surabaya dalam Pembelajaran Matematika Melalui Model Pembelajaran Pemecahan Masalah," Didaktis., vol. 20, no.3, 2020.

[5] N. Yulianty, "Kemampuan Pemahaman Konsep Matematika Siswa dengan Pendekatan Pembelajaran Matematika Realistik," Jurnal Pendidikan Matematika Raflesia., vol. 4, no. 1, Juni 2019.

[6] R. Ananda, "Penerapan Pendekatan Realistics Mathematics Education (RME) untuk Meningkatkan Hasil Belajar Matematika Siswa Sekolah Dasar," Journal Cendekia., vol. 2, no. 1, Mei 2018.

[7] N. Sudjana, Penilaian Hasil Proses Belajar Mengajar, Bandung: PT Remaja Rosdakarya, 2017.

[8] G. Yadrika, "Think-Talk-Write: Strategi untuk Meningkatkan Hasil Belajar Matematika Siswa," JNPM., vol. 3, no.2, September 2019.

[9] V. Damopolii, N. Bito, and R. Resmawan, "Efektifitas Media Pembelajaran berbasis Multimedia pada Materi Segiempat," Algoritm. J. Math. Educ., vol. 1, no. 2, pp. 74-85, 2019, doi: 10.15408/ajme.v1i1.

[10] A. A. Diu, A. D. Mohidin, N. Bito, S. Ismail, and R. Resmawan, "Deskripsi Penggunaan Multimedia Interaktif pada Pembelajaran Matematika Bangun Ruang Sisi Lengkung Tabung,"

Jambura J. Math. Educ., vol. 1, no. 2, pp. 83-89, Oct. 2020, doi: 10.34312/jmathedu.v1i2.7613..

[11] J. Kuswanto, F. Radiansah, "Media Pembelajaran Berbasis Android pada Mata Pembelajaran Sistem Operasi Jaringan Kelas XI," Jurnal Media Infotama., vol. 14, no. 1, 2018.

[12] T. Nurita, "Pengembangan Media Pembelajaran untuk Meningkatkan Hasil Belajar Siswa," Jurnal Misykat., vol.3, no.1, 2018.

[13] D. Waskito, "Media Pembelajaran Interaktif Matematika Bagi Sekolah Dasar Kelas 6 Berbasis Multimedia," Jurnal Sentra Penelitian Engineering dan Edukasi., vol. 9, no. 1, 2019.

[14] P. U. Suseno, Y. Ismail, and S. Ismail, "Pengembangan Media Pembelajaran Matematika Video Interaktif berbasis Multimedia," Jambura J. Math. Educ., vol. 1, no. 2, 2020.

[15] M. Istiqlal, "Pengembangan Multimedia Interaktif dalam Pembelajaran Matematika." JIPMat., vol.2, no.1, Juli 2017.

[16] M. Surur, S. T. Oktavia, "Pengaruh Model Pembelajaran Discovery Learning Terhadap Pemahaman Konsep Matematika," Jurnal Pendidikan Edutama., vol. 6, no. 1, Januari 2019. 